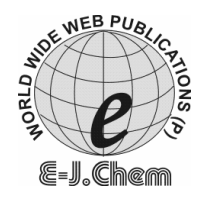

http://www.e-journals.net

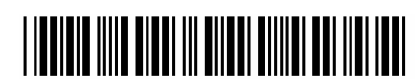

ISSN: 0973-4945; CODEN ECJHAO

E-Journal of Chemistry 2009, 6(3), 743-746

\title{
Synthesis, Characterization and Biological Activity of $\mathrm{Mn}^{2+}, \mathrm{Co}^{2+}, \mathrm{Ni}^{2+}$ and $\mathrm{Cu}^{2+}$ Complexes of Benzoic Acid Ligand
}

\author{
T. ARUNACHALAM* ${ }^{*}$ R. BHAKYARAJ ${ }^{\S}$ and A. K. SASI
}

Department of Chemistry, ${ }^{\S}$ Department of Microbiology, J. J. College of Arts and Science, Pudukkotai, Tamilnadu, India.

aru59@ rediffmail.com

Received 4 October 2008; Accepted 11 December 2008

\begin{abstract}
Metal complex of $\mathrm{Mn}(\mathrm{II}), \mathrm{Co}(\mathrm{II}), \mathrm{Ni}(\mathrm{II})$ and $\mathrm{Cu}(\mathrm{II})$ with benzoic acid have been prepared and characterized by physiochemical methods. On the basis of electronic spectra and magnetic susceptibility measurement in conjunction with infrared spectra, six coordinated octahedral structure have been proposed to all the complexes. The benzoic acid and their complexes have been tested for their antibacterial activity against the bacteria E. coli, Bacillus subtilis, Pseudomonas aeruginosa and Staphylococcus aureus. Further, the non electrolytic nature of all the synthesized complexes was identified from conductivity measurements.
\end{abstract}

Keywords: Benzoic acid ligand, Complexes, Biological activity.

\section{Introduction}

Coordination compounds have been a challenge to inorganic chemist since they were identified in the $19^{\text {th }}$ century. They defy the usual rules of valence at that time and hence called complexes. They play vital role in our lives. Transitions metal complexes with soft or hard donor groups have been used extensively in coordination and organometallic chemistry ${ }^{1}$. Reaction of coordinated ligands model systems of biological interest, analytical chemistry, agriculture and optical display devices ${ }^{2-4}$. The earlier work exhibits metal with thiosemicarbazone as better anticancer agent $t^{5-7}$. There is currently a resurgency of interest in the biochemistry as well as the coordination chemistry of bivalent $\mathrm{Mn}, \mathrm{Co}, \mathrm{Ni}$ and $\mathrm{Cu}$ due to their biological importance. From literature, bivalent metal with Schiff base as ligands were extensively studied towards antimicrobial activity. In view of this and our interest in biologically active coordination compound, the present work communicating the synthesis, characterization and biological activity of $\mathrm{M}^{2+}(\mathrm{M}=\mathrm{Mn}, \mathrm{Co}, \mathrm{Ni}, \mathrm{Cu})$ with benzoic acid as ligand. 


\section{Experimental}

All the chemicals and solvents used were analytical chemistry pure grade. Solvents were purified and dried according to the standard procedure. The ethanolic solution of ligands (Benzoic acid) and ethanolic solution of $\mathrm{M}(\mathrm{II})(\mathrm{Mn}, \mathrm{Co}, \mathrm{Ni}, \mathrm{Cu}$ ) with 1:6 molar ratio were slowly mixed with constant stirring. The mixture was refluxed for $7 \mathrm{~h}$ using water condenser. The resulting solution was reduced to one third its volume and allowed to stand overnight at room temperature. The precipitated crystalline product was separated by using filtration, washed properly with ethanol and dry ether and dried over $\mathrm{CaCl}_{2}$ vaccuo. The solubility of all the complex prepared were checked using solvent DMSO, acetonitrile, water and ethanol. The conductivity of metal complexes was measured in DMSO medium (10 m molar) using Conductivity Bridge, Model Systronics type 304 and a dip type cell which in calibrated with $\mathrm{KCl}$ solution. The magnetic susceptibility and effective magnetic moment (BM) was calculated using Gouy balance (Model: KEYROY). Electronic spectra of all the complex were recorded in nujol mull using Shimadruz MPS-500 spectrophotometer at Alagappa University, Tamilnadu, India. The IR spectrum of complex in nujol mull (using Cesium iodide pellets) was recorded on a Perkin -Elmer 283 spectrophotometer in FTIR region.

Antimicrobial activities of the ligand and the complexes have been carried out against the pathogenic bacteria like Escherichia coli, Bacillus subtilis, Staphylococcus aureus, and Pseudomonas aeruginosa, using nutrient agar medium by disc diffusion method ${ }^{8}$. The test solution were prepared in DMSO and soaked in filter paper of $5 \mathrm{~mm}$ diameter and $1 \mathrm{~mm}$ thickness. These discs were placed on the already seeded plates and incubated at $35{ }^{\circ} \mathrm{C}$ for $24 \mathrm{~h}$. The diameters $(\mathrm{mm})$ of the inhibition zone around each disc were measured after 24 hours. Streptomycin was used as standard.

\section{Results and Discussion}

All the complexes are insoluble in water but soluble in DMSO and acetonitrile. The solubility and stoichiometric composition are listed in Table 1 . The electrolytic conductance data in DMSO at the concentration $10^{-3}$ molar suggest the non electrolytic nature of all complexes. Further the absence of any color change in DMSO reveals us there in no distortion in their geometry. The magnetic moment value for all the complexes corresponds to high spin M(II) ion. The details are given in Table 2.

Table 1. Stoichometric composition and solubility of synthesized complexes.

\begin{tabular}{cccccc}
\hline \multirow{2}{*}{ Complexes } & $\begin{array}{c}\text { Mole of } \\
\text { metal ion }\end{array}$ & $\begin{array}{c}\text { Mole of } \\
\text { ligand }\end{array}$ & Water & DMSO & Acetonitrile \\
\hline Mn L' ${ }_{6}$ & 0.03 & 0.1819 & Insoluble & Soluble & Soluble \\
$\mathrm{Co} \mathrm{L}_{6}{ }_{6}$ & 0.02 & 0.1236 & Insoluble & Soluble & Soluble \\
$\mathrm{Cu} \mathrm{L}_{6}{ }_{6}$ & 0.035 & 0.2116 & Insoluble & Soluble & Soluble \\
$\mathrm{Ni} \mathrm{L}_{6}{ }_{6}$ & 0.025 & 0.1415 & Insoluble & Soluble & Soluble \\
\hline
\end{tabular}

Table 2. Magnetic moment and conductivity.

\begin{tabular}{ccccc}
\hline \multirow{2}{*}{ Complex } & \multicolumn{2}{c}{ Magnetic behavior } & \multicolumn{2}{c}{ Conductivity } \\
\cline { 2 - 5 } & $\begin{array}{c}\text { Mag. susceptibility, } \\
\text { cgs unit }\end{array}$ & $\mu_{\mathrm{eff}}(\mathrm{BM})$ & $\begin{array}{c}\text { Conductance, } \\
\mathrm{Ohm}^{-1}\end{array}$ & $\begin{array}{c}\text { Molar conductance, } \\
\mathrm{Ohm}^{-1} \mathrm{~cm}^{2} \mathrm{~mol}^{-1}\end{array}$ \\
\hline Mn L'$_{6}$ & 0.0106 & 5.13 & $0.01 \times 10^{-3}$ & 21.27 \\
Co L $_{6}{ }_{6}$ & $5.648 \times 10^{-3}$ & 3.17 & $210 \times 10^{-3}$ & 47.39 \\
Ni L $_{6}{ }_{6}$ & $1.059 \times 10^{-3}$ & 1.613 & $11.7 \times 10^{-6}$ & 24.38 \\
$\mathrm{Cu} \mathrm{L}_{6}$ & $2.946 \times 10^{-3}$ & 2.7 & $11.8 \times 10^{-6}$ & 25.26 \\
\hline
\end{tabular}


The reflectance spectrum of Mn complexes with benzoic acid shows five bands. The weak bands are due to $d-d$ transition from high spin $\mathrm{d}^{5}$ configuration involving spin paring. Further there is only one way of arranging five electrons with parallel spin in five orbitals, however there are many ways if two of these electrons are paired. The broad band at $13333 \mathrm{~cm}^{-1}$ for $\mathrm{Cu}$ (II) complex suggesting that are tetragonal type. The spin allowed transition of $\mathrm{Co}$ (II) complexes with benzoic acid was identified at $25000 \mathrm{~cm}^{-1}$. A broad band for $\mathrm{Ni}(\mathrm{II})$ at $23000 \mathrm{~cm}^{-1}$ confirm the octahedral geometry. The absence any band below $1000 \mathrm{~cm}^{-1}(10 \mathrm{Dq})$ eliminates the possibility of tetrahedral environments. The characteristic band and its transitions are given in Table 3 .

The IR spectra of the benzoic acid and the corresponding metal complexes have been compared in order to fix the mode of bonding of the benzoic acid in the metal complexes. The benzoic acid shows strong band at $1700 \mathrm{~cm}^{-1}-1630 \mathrm{~cm}^{-1}$ characteristic of $(\mathrm{C}=\mathrm{O})_{\mathrm{st}}$ frequency. The IR spectrum of corresponding complexes this band is shifted to lower frequency region $1510-1525 \mathrm{~cm}^{-1}$. The broad band at $3513-3300 \mathrm{~cm}^{-1}$ is for $(\mathrm{O}-\mathrm{H})_{\mathrm{st}}$ frequency in free ligand with the intramolecular hydrogen bonding and the same band appeared in the complexes, indicating the absence of deprotonation of the benzoic acid group. The above discussion confirm that the coordination through only $(\mathrm{C}=\mathrm{O})$ group, not through $(\mathrm{O}-\mathrm{H})$ group. Absence of any band around $880 \mathrm{~cm}^{-1}$ indicating the absence of coordination by atmospheric water. The details are shown in Table 3.

Table 3. Electronic and IR spectral data.

\begin{tabular}{|c|c|c|c|c|c|}
\hline \multirow{3}{*}{ Complex } & \multirow{3}{*}{$\begin{array}{l}\text { Electric spectra } \\
\qquad \mathrm{cm}^{-1}\end{array}$} & \multicolumn{4}{|c|}{ IR Frequency, $\mathrm{cm}^{-1}$} \\
\hline & & \multicolumn{2}{|c|}{ Absence of metal } & \multicolumn{2}{|c|}{ In complex } \\
\hline & & $(\mathrm{C}=\mathrm{O})_{\mathrm{st}}$ & $(\mathrm{O}-\mathrm{H})_{\mathrm{st}}$ & $(\mathrm{C}=\mathrm{O})_{\mathrm{st}}$ & $(\mathrm{O}-\mathrm{H})_{\mathrm{st}}$ \\
\hline $\mathrm{Mn} \mathrm{L}_{6}$ & $\begin{array}{c}18900,23100,24970 \\
28000 \& 29700\end{array}$ & 1700 & 3000 & 1510 & 3000 \\
\hline $\mathrm{Co} \mathrm{L}_{6}$ & $\begin{array}{c}17250,25000 \& \\
35700\end{array}$ & 1700 & 3000 & 1510 & 3000 \\
\hline $\mathrm{Ni} \mathrm{L}_{6}$ & 23000 & 1700 & 3000 & 1510 & 3000 \\
\hline $\mathrm{Cu} \mathrm{L}_{6}{ }_{6}$ & 13333 & 1700 & 3000 & 1510 & 3000 \\
\hline
\end{tabular}

Antibacterial activity of ligand and corresponding complexes are recorded in Table 4. It has been observed that the metal complex have a high activity than ligand against same organisms under the identical experimental condition. The result show that the activity enhances from $\mathrm{Mn}^{2+}$ to $\mathrm{Cu}^{2+}$ on charge density increases. This can be understood when electrons are draining from metal to ligand by back donation will facilitate the intramolecular hydrogen bonding between coordinated ligands and slowly approaching the chelating character, which subsequently favor lipophilic nature of central metal ion in permeation through the lipid layer of membrane ${ }^{8}$.

Table 4. Antimicrobial activity of compounds (Diameter of inhibition zone in $\mathrm{mm}$ and concentration in ppm).

\begin{tabular}{ccccccccc}
\hline \multirow{2}{*}{ Compound } & \multicolumn{2}{c}{ E. coli } & \multicolumn{2}{c}{ B. subtilis } & \multicolumn{2}{c}{ P. aeruginosa } & \multicolumn{2}{c}{ S. aureus } \\
\cline { 2 - 9 } & 500 & 1000 & 500 & 1000 & 500 & 1000 & 500 & 1000 \\
\hline Ligand & 5.0 & 6.2 & 5.4 & 5.9 & 6.7 & 3.1 & 7.0 & 8.2 \\
Mn L' & 9.0 & 10 & 8.0 & 9.0 & 10 & 11 & 10.5 & 12.0 \\
Co L' & 10.2 & 12 & 9.1 & 10.5 & 11 & 12.6 & 11.7 & 16.5 \\
Cu L' & 11.0 & 13.8 & 10.2 & 12.1 & 12.1 & 13.9 & 12.2 & 15.4 \\
Ni L'6 & 12.0 & 14.6 & 11.5 & 13.5 & 13.2 & 15.2 & 13.5 & 16.2 \\
Standard & 22 & 24 & 24.2 & 26.5 & 20.1 & 22.3 & 22.0 & 23.5 \\
\hline
\end{tabular}




\section{Conclusion}

All the complexes are octahedral geometry and paramagnetic nature. They show remarkable activity against all the organism tested. The mode of action of complexes may involve the formation of hydrogen bonds involving the benzoic acid group with microbial or ribosome of the microbial cells resulting in interference with normal cell process. The toxicity increases with increasing concentration of the complexes.

\section{References}

1. Sarkar A R and Mandal S, Synth React Inorg Met-Org Chem., 2000, 80, 1477.

2. Mishra A P and Khare M, Indian J Chem Soc., 2000, 77, 367.

3. Siddiqui R S and Nishat N, Synth React Inorg Met-Org Chem., 2000, 30,1005.

4. Maurya M R and Bharatia N, Transition Met Chem., 1993, 23, 5.

5. Subezynski W K, Anholine W E, Hyde J E and Petering O H, J Am Chem Soc., 1987, 109, 46.

6. Murugkar A, Unnikrishnan S B, Padhye S, Treat Triantafullan E and Sinn E, Metal Based Drugs, 1999, 6, 177.

7. Agarwal K C and Santorelli A C, Prog Med Chem., 1978, 15, 351.

8. Tweedy B G, Phytopathology, 1964, 55, 910. 


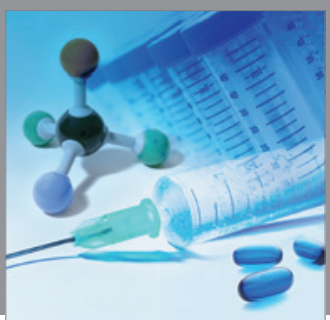

International Journal of

Medicinal Chemistry

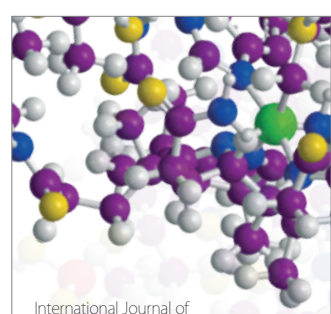

Carbohydrate Chemistry

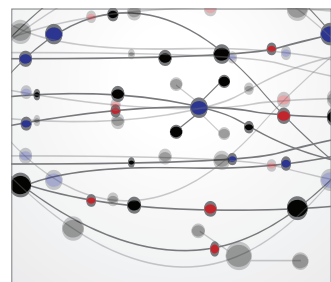

The Scientific World Journal
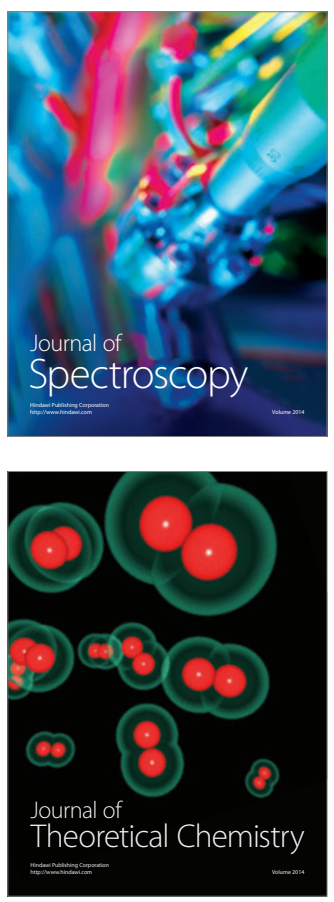
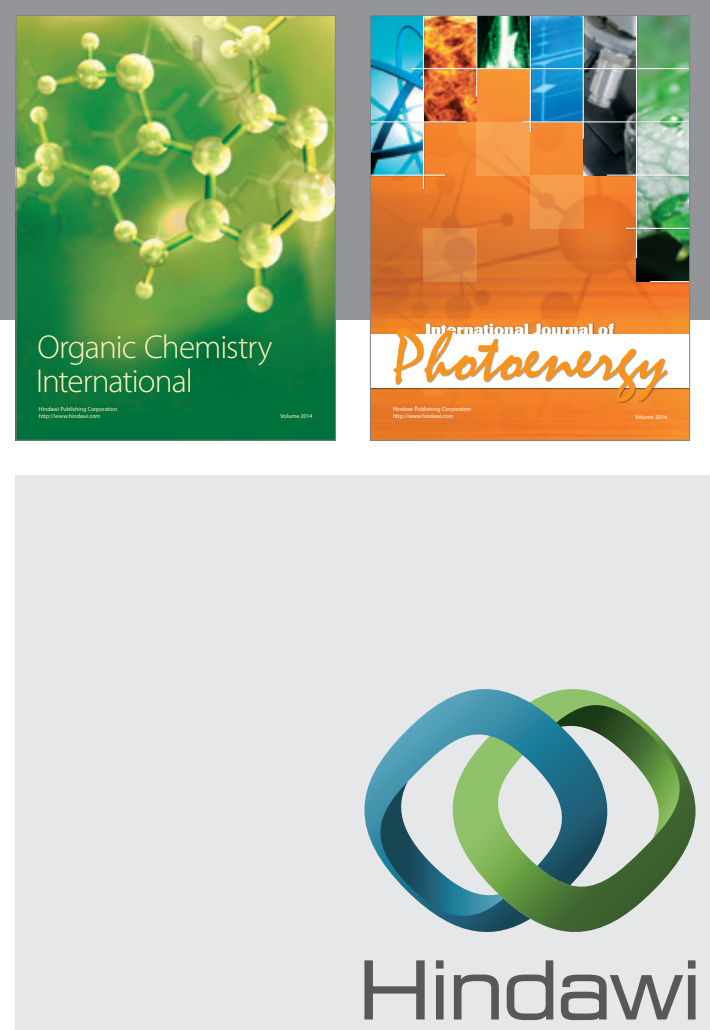

Submit your manuscripts at

http://www.hindawi.com
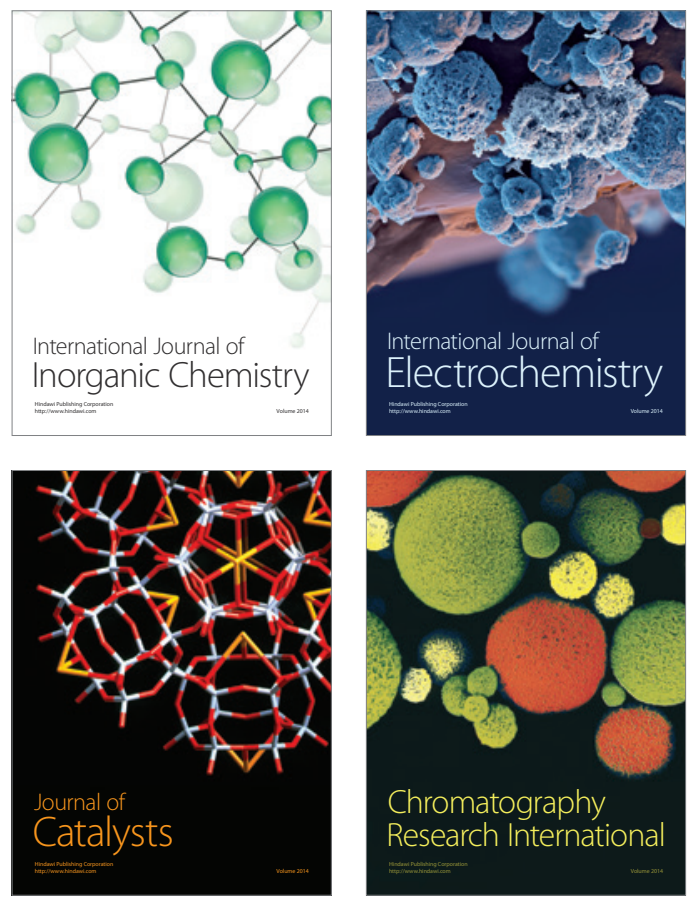
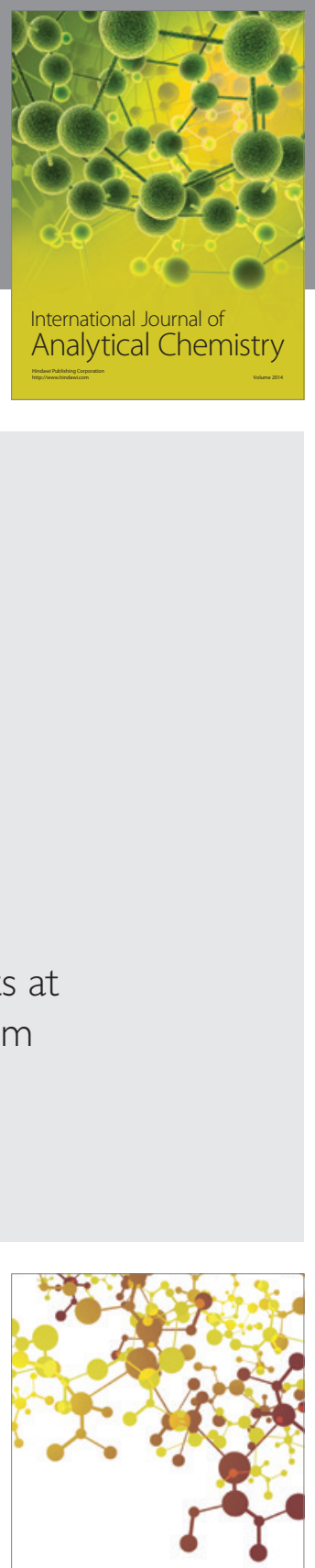

Journal of

Applied Chemistry
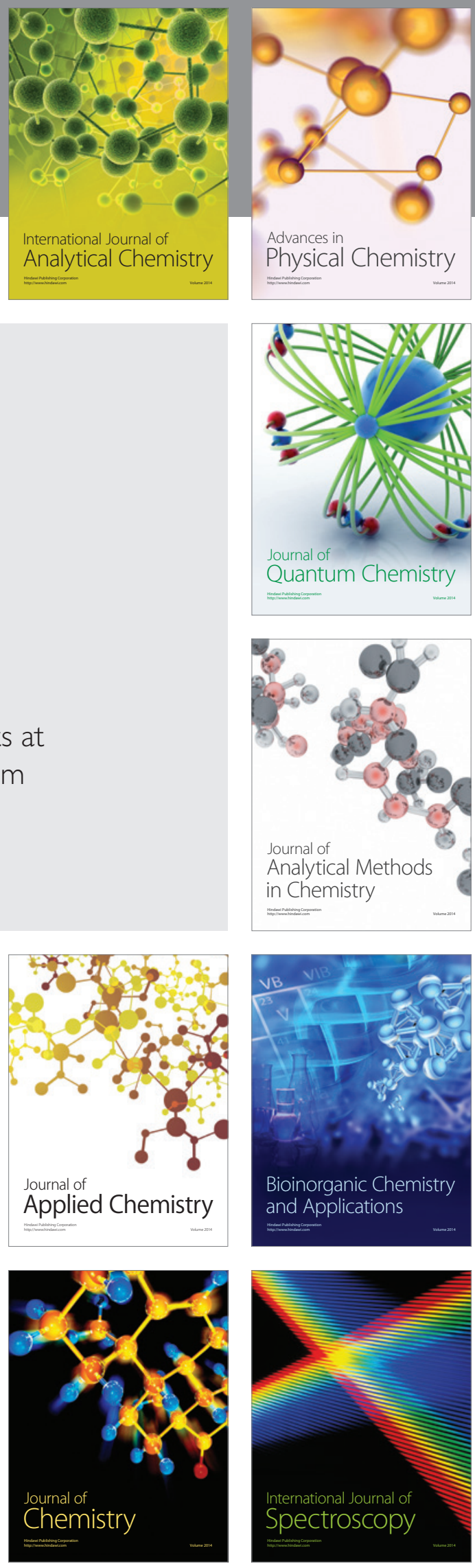